\title{
Selected Options for Modelling of Transport Processes Particularly in Relation to Intermodal Transport
}

\author{
Jozef Gnap ${ }^{1}$, and Jaroslava Kubáňová ${ }^{1, *}$ \\ ${ }^{1}$ University of Žilina, Faculty of Operation and Economics of Transport and Communications, \\ Department of Road and Urban Transport, Univerzitná 1, 010 26, Žilina, Slovak Republic
}

\begin{abstract}
The first specialized road-rail combined transport operators were founded by road hauliers, who experienced road capacity bottlenecks and collaborating railways in the late 1960s in Europe. Combined transport is thus the optimal embodiment of the European concept of co-modality, whereby the strengths of both participating modes of transport - road and rail - can best be exploited: the flexibility of road transport in pre- and post- haulage, while the low energy need, safety, speed and reliability of rail transport.
\end{abstract}

\section{Introduction}

Multimodal transport - is the movement of cargo from origin to destination by several modes of transport where each of these modes have a different transport provider or entity responsible, but under a single contract. A Single carrier contracted to fulfil a single journey [1].

Intermodal transport - is the movement of goods in one and the same loading unit or road vehicle, which uses successively two or more modes of transport without handling the goods themselves in changing modes. By extension, the term intermodality has been used to describe a system of transport whereby two or more modes of transport are used to transport the same loading unit or truck in an integrated manner, without loading or unloading, in a door to door transport chain [1].

Combined transport - is a form of intermodal transport, which is the movement of goods in one and the same loading unit or road vehicle, using successively two or more modes of transport without handling the goods themselves in changing modes. Combined transport is intermodal transport where the major part of the journey is by rail, inland waterways or sea, and any initial and/or final legs carried out by road are as short as possible [1].

The negative consequences of transport such as pollution, climate change, noise, congestion and accidents pose problems to the economy, health and well-being of European citizens. Freight transport continues to grow and road freight transport, in particular, is projected to increase by around $40 \%$ by 2030 and by little over $80 \%$ by 2050 . The EU

* Corresponding author: jaroslava.kubanova@ffpedas.uniza.sk 
transport policy aims therefore at reducing road transport towards less polluting and more energy efficient modes of transport [2].

Four types of actions support greater use of intermodal solutions.

1. The internalisation of external costs in all modes of transport, with a view to send appropriate pricing signals to users, operators and investors. The social and environmental costs of transport should be paid in line with the polluter pays principle.

2. More targeted investments into physical infrastructure, aimed at better interconnections between the single modal networks.

3. Better used of information (on traffic, capacities, availability of infrastructure, cargo and vehicle positioning).

4. Direct support for intermodal transport, as provided by the Combined Transport Directive (Council Directive 92/106/EEC), which aims to increase the competitiveness of the combined transport (defined as intermodal transport with a strictly limited road leg). The EU also provides financial support to multimodal/intermodal transport [3].

The following definitions are given by the United Nations Economic Commission for Europe: Combined transport is intermodal transport where the major part of the European journey is by rail, inland waterways or sea and any initial and/or final legs carried out by road are as short as possible.

\section{Selected techniques of combined transport}

\subsection{Rail - Road}

\section{Lorry}

Lorries make it possible to provide a door-to-door service, as they cover the short distances separating factories and terminals. They enable the major advantages of road haulage to be tapped, i.e. a network that reaches further and is denser.

\section{Container}

Containers lead to better logistical management of the areas used for loading and unloading goods, since their rigid structure enables up to six of them to be stacked in one pile. Container lengths have been standardised at between 20 and 53 feet.

\section{Swap body}

Swap bodies are standardised loading units equally suitable for carriage on road vehicles or railway wagons. As they can be used in a broad range of situations, are simple in design and inexpensive, and this form of conveyance has been highly successful and is currently one of the most widely used transport systems on the market.

\section{Semi-trailer}

While semi-trailers are more costly and heavier, their advantage is that they can be coupled directly to a tractor and do not require a road chassis, unlike containers and swap bodies.

\section{Terminal}

Terminals are interchange hubs between rail and road traffic. They are fitted with all the equipment required to handle and tranship loading units from one transport mode to the next in a rapid and efficient manner: gantries and mobile cranes, modern computer systems integrating tracks, storage areas, transhipment areas and connections to roads and motorways [4]. 


\subsection{Benefits of combined transport}

Combined Transport presents a range of benefits. It contributes towards a better quality of life and proposes a seamless transport solution in order to improve the productivity of the entire chain.

The main benefits of combined transport can be summarised as follows:

- Friendly towards the environment: on routes where volumes can be bundled and distance is appropriate, combined transport provides substantial energy gains and lower $\mathrm{CO} 2$ emissions.

- Friendly towards society: reduces accidents, road congestion and dependency on energy reserves.

- It allows for a better use of existing capacity.

- It combines the flexibility of road with the economies of rail on long journeys for large volumes.

- It is well integrated in the logistics chain.

- It is safe and secure: reduce risk for goods during the transport journey.

\section{Rail/road combined transport in Europe}

Combined transport (CT) represents an important cornerstone of the European freight market (see Fig. 1).

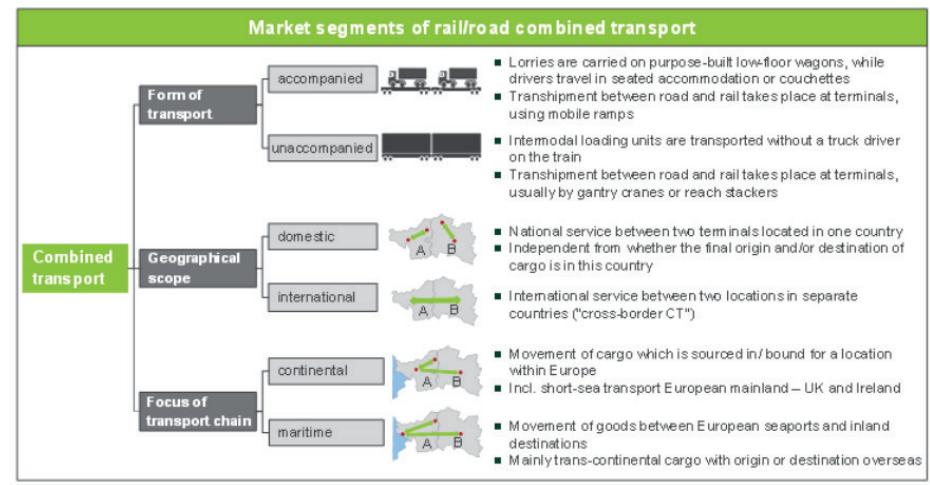

Fig. 1. Overview of market segments in rail/road combined transport. Source: [5]

The total volume of combined transport in Europe, including unaccompanied and accompanied combined transport, adds up to 21,0m TEU in 2015. Compared to 2013, the total combined transport volume recorded a slight increase of $+1 \%$ (see Fig. 2).

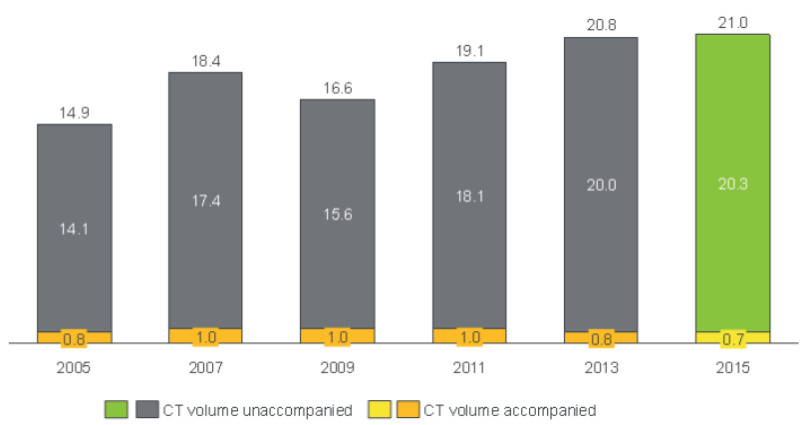

Fig. 2. Development of total combined transport volumes 2005 to 2015 in million TEU. Source: [5] 
Based on the total CT tonnage transported, the increase amounts to approx. $+8.5 \%$ from 2013 to 2015 and is therefore considerably higher than the growth in TEU. The positive development of the overall CT market is the same for both measurements in TEU and in tonnes. However, the stronger growth of tonnes in contrast to TEU indicates a trend towards transporting heavier shipments than some years ago. The following table depicts the total CT market development from 2005 to 2015.

Table 1. Development of total combined transport volumes 2005 - 2015 in million tonnes. Source: [5]

\begin{tabular}{|c|c|c|c|c|c|c|}
\hline Segment & 2005 & 2007 & 2009 & 2011 & 2013 & 2015 \\
\hline $\begin{array}{c}\text { CT volume } \\
\text { unaccompanied }\end{array}$ & 145.5 & 181.5 & 164.6 & 191.8 & 203 & 218 \\
\hline $\begin{array}{c}\text { CT volume } \\
\text { accompanied }\end{array}$ & 10.2 & 13.6 & 15.1 & 14.9 & 10.8 & 13 \\
\hline Total & 155.7 & 195.1 & 179.7 & 206.7 & 213.8 & 231 \\
\hline
\end{tabular}

The total CT market increase is mainly driven by volumes of the unaccompanied segment, while the accompanied CT volume increased in tonnage and is approaching the level of 2011. In 2015, the unaccompanied CT segment's market share amounts to approx. $94 \%$ of the total CT market. Consequently, nearly $90 \%$ of the CT providers offer unaccompanied CT services, while only $1 \%$ is focused on accompanied CT and approx. $10 \%$ provide both unaccompanied and accompanied CT services [6].

\subsection{Transportation of intermodal units by Bohemiakombi transport operator}

Bohemiakombi is a key Czech combined transport operator. Their aim is to move goods flows from the roads to the railways, which provides users with marked benefits, such as various legislative exceptions.

When planning transport, what is very important for them are the interests of the road haulier, which they try to harmonise with the options provided by railways, thereby ensuring reliable, fast and environmentally-friendly transport. There are several reasons to work with them:

- They coordinate mutually beneficial co-operation between road and rail transport companies.

- The goods are never handled - they load the whole unit onto a railway truck.

- Rail transport is not as limited as road transport (e.g. the ban on lorries on roads at weekends and on public holidays, higher weights, etc.).

Handling system in the terminal of Bohemiakombi is depicted in following Fig. 3.

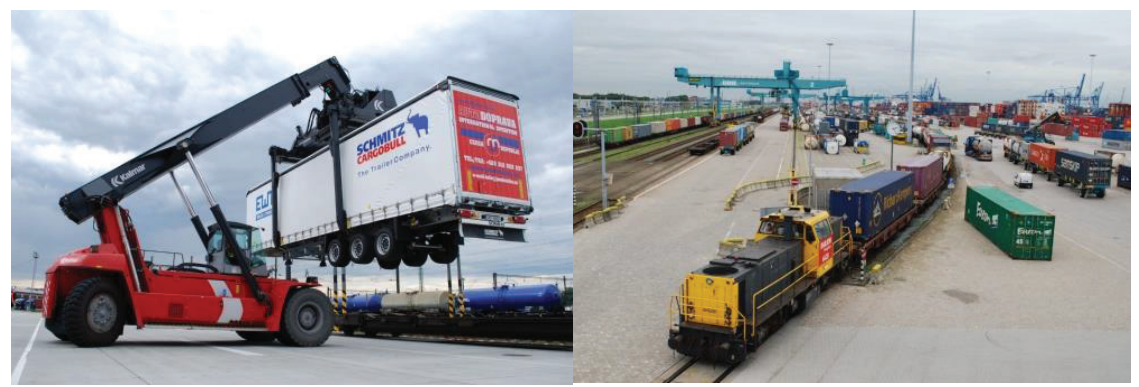

Fig. 3. Handling system in the terminal of Bohemiakombi. Source: [7]

Through their system of complete combined transport trains they offer fast, reliable and regular links to industrial areas in the Ruhr, Baden, northern Germany, the Benelux, 
Scandinavia, Italy and other places. In the Czech Republic they arrange follow-on rail transport to Czech and Slovak combined transport transhipment points, Poland and Austria. They also transport freight directly to the customer's industrial spur line. At the current time their company operates on the following transport lines:

- Lovosice - Duisburg/Rotterdam v. v.

- Lovosice - Hamburg v. v.

- Lovosice - Antwerpen v.v.

- Ostrava (Paskov) - Duisburg/Hamburg/Antwerpen/Rotterdam v.v.

- Brno - Duisburg/Hamburg/Antwerpen/Rotterdam v.v.

- Přerov - Duisburg/Hamburg/Antwerpen/Rotterdam v.v.

- Brno - Rostock v. v.

\section{Transport condition}

Orders are accepted by our sales department. Orders for transport on the regular lines have to be delivered by 10 a.m. one day before the end of loading. The orders must contain:

- the loading unit no.,

- requested relation,

- date of transport,

- type and length of the loading unit,

- gross and net weight of the unit,

- information about RID (class, UN number, name of the goods, packing group).

\section{Line: Lovosice CD - DUSS - Duisburg-Ruhrort Hafen Ubf DUSS}

\section{Timetable:}

From Monday to Thursday

Saturday:

Departure: 7:45 p.m.

Departure: 9:30 a.m.

Arrival: 12:40 p.m.

Arrival: 5:40 a.m.

Duration: $16: 55$

Duration: 1day 20hours

\section{Comparison of road freight transport and intermodal transport}

In this article, we compare just delivery of the load in a purely time perspective. And we design a procedure for calculating the number of trailers required to operate one complete train with intermodal semitrailers. In the future, it would be interesting to compare the costs of each type of transport.

\section{Intermodal transport}

If we check Bohemiacombi's timetable (from Monday to Thursday), we can see that the transfer from the Lovosice CD-DUSS to Duisburg-Ruhrort Hafen Ubf DUSS line runs about 17 hours.

\section{Road freight transport}

Through the planner program Viamichelin we find the recommended route (see Fig.4). 


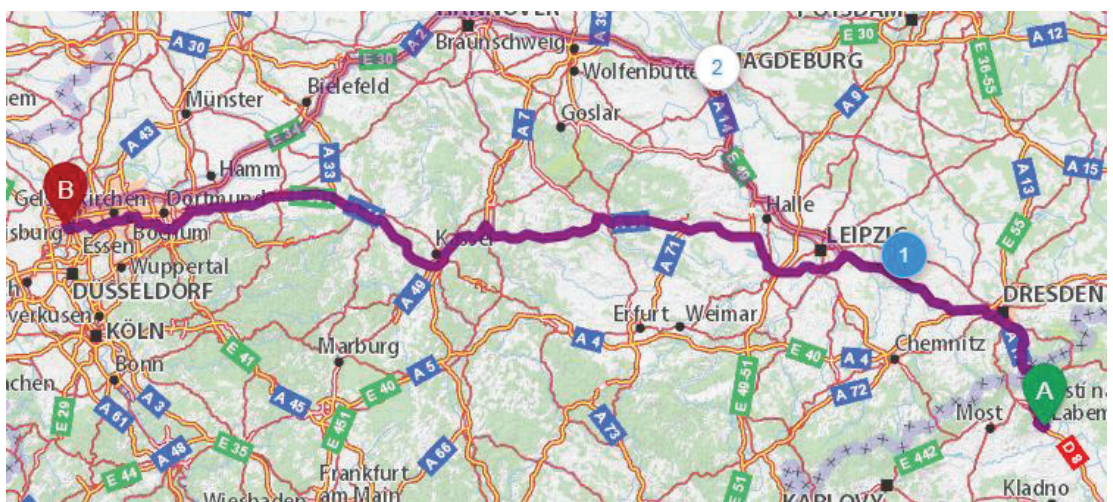

Fig. 4. The route from Lovosice to Duisburg. Source: [8]

This route includes motorways, rather $644 \mathrm{~km}$ on motorways of total approx. $690 \mathrm{~km}$. We schedule daily driving periods and breaks for one driver taking into account REGULATION (EC) No 561/2006 OF THE EUROPEAN PARLIAMENT AND OF THE COUNCIL of 15 March 2006 on the harmonisation of certain social legislation relating to road transport.

Distance: $690 \mathrm{~km}$

Average speed: $60 \mathrm{~km} / \mathrm{h}$

Crew: monomial crew

Start: 7:45 p.m.

Daily driving periods and breaks for one driver with regular daily rest period are summarized in following Table 2 and 3.

Table 2. Daily driving periods and breaks for one driver with regular daily rest period. Source: authors

\begin{tabular}{|c|c|c|c|}
\hline Start & Finish & Mode & Duration \\
\hline 7:45 p.m. & 0:15 a.m. & driving & 4.5 hour \\
\hline 0:15 a.m. & $1: 00$ a.m. & break time & 45 min \\
\hline 1:00 a.m. & 5:30 a.m. & driving & 4.5 hour \\
\hline 5:30 a.m. & $4: 30$ p.m. & rest period & 11 hour \\
\hline 4:30 p.m. & 7:00 a.m. & driving & 2.5 hour \\
\hline
\end{tabular}

Total time: 23 hour 15 minute

Table 3. Daily driving periods and breaks for one driver with reduced daily rest period. Source: authors

\begin{tabular}{|c|c|c|c|}
\hline Start & Finish & Mode & Duration \\
\hline 7:45 p.m. & 0:15 a.m. & driving & 4.5 hour \\
\hline 0:15 a.m. & $1: 00$ a.m. & break time & 45 min \\
\hline 1:00 a.m. & 5:30 a.m. & driving & 4.5 hour \\
\hline 5:30 a.m. & $2: 30$ p.m. & rest period & 9 hour \\
\hline 2:30 p.m. & 5:00 a.m. & driving & 2.5 hour \\
\hline
\end{tabular}

\section{Total time: 21 hour 15 minute}

If we compare delivery times, it is better to use intermodal transport. And that's just a time reason.

If we looked at other benefits, they are:

- increases the available working time of drivers,

- minimizing the risks associated with road transport (congestion, stealing of cargo, atc.),

- avoid driving bans,

- to keep the minimum wage paid to the driver in Germany, 
- exemption from road tax and toll payment,

- higher delivery speed,

- transfer of road loads to the railways,

- impact on the environment, etc.

However, the continued growth of road transport presents challenges when it comes to traffic congestion, road safety, and air pollution. Though trucks can provide door-to-door convenience, it is imperative that suppliers and governing bodies facilitate intermodal approaches to freight. Intermodal transport, sometimes referred to as combined transport, is the movement of cargo using two or more means - including road, rail, air, and sea. The term is also used interchangeably with intermodal transport, in which goods are transported in a single intermodal container using multiple transport modes [9].

Transport operators have to understand that public infrastructure sets a general limit to the size of vehicles and combined transport loading units, and that any developments in this area must comply with rules for this type of infrastructure. The road networks seems to pose the fewest constraints, mainly because road vehicle manufactures are able to offer chassis and trucks with relatively low platforms if the operator is willing to pay extra for the special design and small-diameter tires. Carriers tend to use combined transport. They think this is the future of long-distance transport within Europe. Although after-sales services are still cheap, they see more advantages than disadvantages. The main problem is to convince the customer that his goods will be partly transported by road and partly by rail.

\subsection{Designing a procedure for calculating the number of trailers required to operate one complete train with intermodal semitrailers}

A complete train departs from the Lovosice terminal; it means the maximum number of intermodal semi-trailers per line is 20 . The terminal operates 9 hours per day. The attractive area of customers, from which intermodal trailers are imported, has a range of $30 \mathrm{~km}$. The trailers run at an average speed of $55 \mathrm{~km} / \mathrm{h}$. The handling time with the semi-trailer in customers is $25 \mathrm{~min}$, and the handling time in terminal takes $20 \mathrm{~min}$ per one semitrailer on average.

\section{Calculation of trailers turn-over time:}

$$
\begin{aligned}
& \text { Tto }=[(2 * l z) / v t]+t h c+t h t \\
& \text { Tto }=[(2 * 30) / 55]+0.42+0.33=1.84 h
\end{aligned}
$$

where: Tto - trailer's turn-over time; thc - handling time in customers; tht - handling time in the terminal; $1 \mathrm{z}$ - transport distance; $\mathrm{vt}$ - the technical speed of the trailer [10]

Calculation of number of trailers turnarounds per day:

$$
\begin{aligned}
& P o=D W T / \text { Tto } \\
& P o=9 / 1.84=4.89 \text { ○ } 5 \text { turnarounds }
\end{aligned}
$$

where: Po - number of trailers turnarounds per day; DWT - daily working time

\section{Calculation of required number of trailers:}

$$
\begin{aligned}
& T R=P N / P o \\
& T R=20 / 5=4 \text { trailers }
\end{aligned}
$$

where: TR - required number of trailers; $\mathrm{PN}$ - number of semi-trailers

Thus, we need four trailers to operate a complete train from Lovosice terminal. 


\section{Conclusion}

For in-line hauls, combined transport will use the installations specific to the mode on each leg. In additional, it needs facilities to change from one mode to the other. These will be found mainly in the terminals, combined transport cannot thus do without terminal equipment. However, as is the case with freight transport, poor connectivity can create a barrier to intermodalism [11].

Creating hubs or terminals is perhaps the most crucial step for combined transport. Intermodal transport is essential for removing passenger and freight vehicles from road networks worldwide. As many nations strive to meet carbon emissions targets and make their roads safer, it is crucial that commuters and suppliers discover alternate modes of movement. If public and private sector bodies combine capital and resources to streamline shifts from mode to mode, it will undoubtedly result in safer and more sustainable roads. Intermodal transport can best provide sustainable transport solutions once the right infrastructure and management solutions are in place. But cargo isn't the only thing that moves more sustainably using multiple modes of transport.

This paper is supported by the research project "From horse-drawn railway to intermodal transport" within Visegrad Fund.

\section{References}

1. J. Gnap, Modelovanie dopravného a prepravného procesu v cestnej nákladnej doprave, 1 st ed., 120 p. (University of Zilina, Slovak Republic, 2013)

2. L. Moravcik, Transport and communications 1 (2010)

3. I. Kubasakova, R. Kampf, O. Stopka, Communications: scientific letters of the University of Žilina 16, 2, 9-13 (2014)

4. O. Stopka, R. Kampf, J. Kolar, I. Kubasakova, Ch. Savage, Communications: scientific letters of the University of Žilina 16, 2, 14-19 (2014)

5. L. Wattignies, Combined transport in Europe, Available online: http://uic.org/IMG/pdf/2016_report_on_combined_transport_in_europe_cles.pdf (2017)

6. M. Poliak, Journal of Economics, 206-220 (2013)

7. J Weise, Available online: https://www.kombiverkehr.de/en/transport/\#fahrplan (2017)

8. I. Fišer, Available online: http://bohemiakombi.cz (2017)

9. J. Kapusta, A. Kalašová, Scientific journal of Silesian University of technology series: Transport 93, 49-58 (2016)

10. I. Kubasakova, J. Jagelcak, Communications: scientific letters of the University of Žilina 18, 2, 109-112 (2016)

11. S. Kubíková, A. Kalašová, L. Černický, TST 2014 - Telematics - support of transport, 414-423 (Katowice/Kraków/Ustroń, Poland, 2014) 